\title{
Front Matter: Volume 9882
}

, "Front Matter: Volume 9882," Proc. SPIE 9882, Remote Sensing and Modeling of the Atmosphere, Oceans, and Interactions VI, 988201 (3 August 2016); doi: 10.1117/12.2242953

SPIE. Event: SPIE Asia-Pacific Remote Sensing, 2016, New Delhi, India 


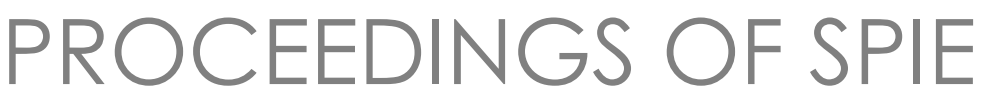

\title{
Remote Sensing and Modeling of the Atmosphere, Oceans, and Interactions VI
}

\author{
Tiruvalam N. Krishnamurti \\ Madhavan Nair Rajeevan \\ Editors
}

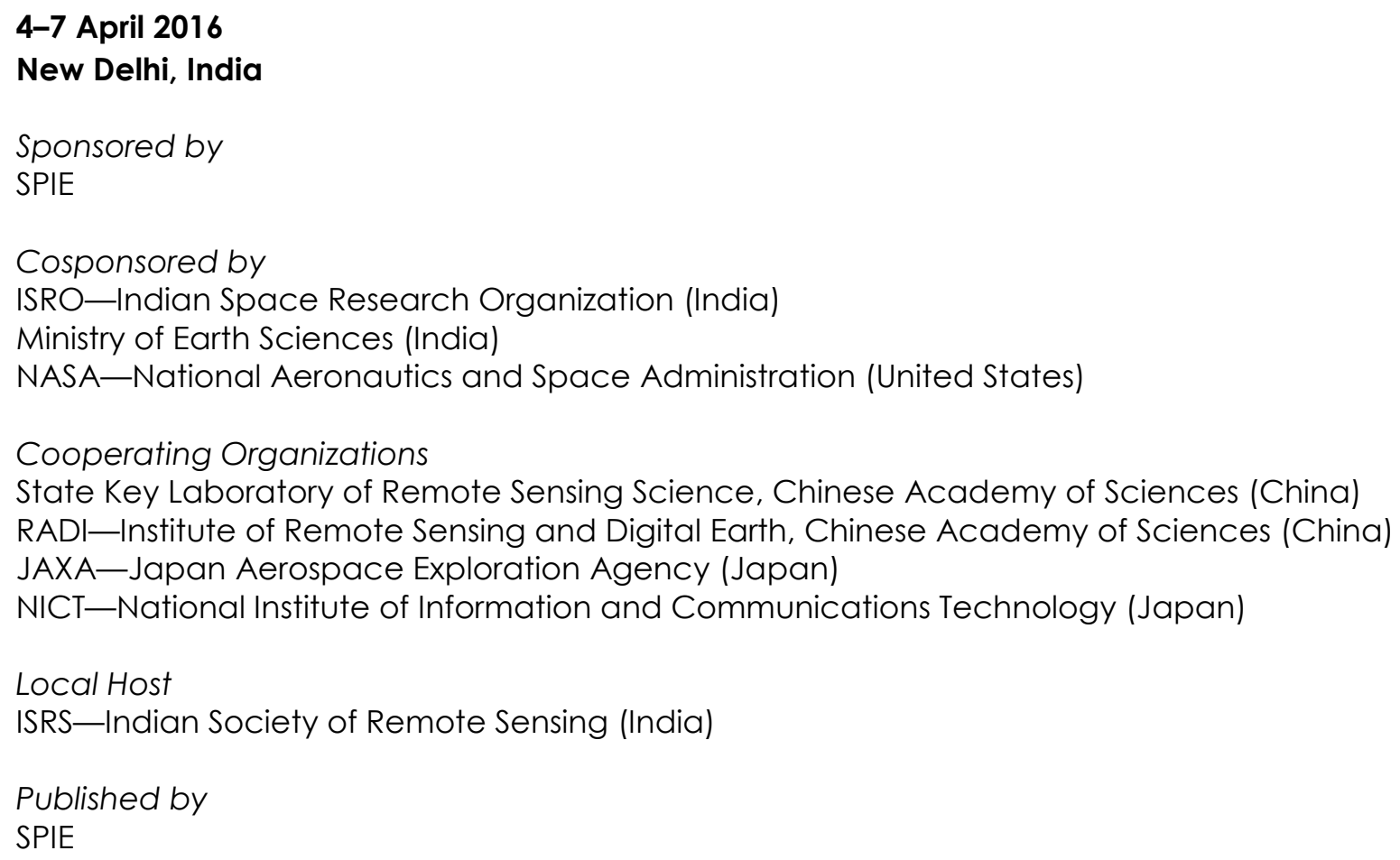

Volume 9882 
The papers in this volume were part of the technical conference cited on the cover and title page. Papers were selected and subject to review by the editors and conference program committee. Some conference presentations may not be available for publication. Additional papers and presentation recordings may be available online in the SPIE Digital Library at SPIEDigitallibrary.org.

The papers reflect the work and thoughts of the authors and are published herein as submitted. The publisher is not responsible for the validity of the information or for any outcomes resulting from reliance thereon.

Please use the following format to cite material from these proceedings:

Author(s), "Title of Paper," in Remote Sensing and Modeling of the Atmosphere, Oceans, and Interactions VI, edited by Tiruvalam N. Krishnamurti, Madhavan Nair Rajeevan, Proceedings of SPIE Vol. 9882 (SPIE, Bellingham, WA, 2016) Six-digit Article CID Number.

ISSN: 0277-786X

ISSN: 1996-756X (electronic)

ISBN: 9781510601239

Published by

SPIE

P.O. Box 10, Bellingham, Washington 98227-0010 USA

Telephone +1 3606763290 (Pacific Time) · Fax +1 3606471445

SPIE.org

Copyright (C) 2016, Society of Photo-Optical Instrumentation Engineers.

Copying of material in this book for internal or personal use, or for the internal or personal use of specific clients, beyond the fair use provisions granted by the U.S. Copyright Law is authorized by SPIE subject to payment of copying fees. The Transactional Reporting Service base fee for this volume is $\$ 18.00$ per article (or portion thereof), which should be paid directly to the Copyright Clearance Center (CCC), 222 Rosewood Drive, Danvers, MA 01923. Payment may also be made electronically through CCC Online at copyright.com. Other copying for republication, resale, advertising or promotion, or any form of systematic or multiple reproduction of any material in this book is prohibited except with permission in writing from the publisher. The CCC fee code is 0277-786X/16/\$18.00.

Printed in the United States of America.

Publication of record for individual papers is online in the SPIE Digital Library.

\section{SPIE. DIGITAL}

Paper Numbering: Proceedings of SPIE follow an e-First publication model. A unique citation identifier (CID) number is assigned to each article at the time of publication. Utilization of CIDs allows articles to be fully citable as soon as they are published online, and connects the same identifier to all online and print versions of the publication. SPIE uses a six-digit CID article numbering system structured as follows:

- The first four digits correspond to the SPIE volume number.

- The last two digits indicate publication order within the volume using a Base 36 numbering system employing both numerals and letters. These two-number sets start with 00, 01, 02, 03, 04, 05, 06, 07, 08, 09, OA, OB ... 0Z, followed by 10-1Z, 20-2Z, etc. The CID Number appears on each page of the manuscript. 


\title{
Contents
}

\author{
vii Authors \\ ix Symposium Committees \\ xi Conference Committee
}

\section{AEROSOL, CLOUD, AND PRECIPITATION I}

988204 MODIS sea surface temperature retrievals using different channel combinations and hybrid cloud detection [9882-4]

988205 Towards understanding the variability of aerosol characteristics over the Indo-Gangetic Plain [9882-5]

\section{AEROSOL, CLOUD, AND PRECIPITATION II}

988207 Evaluation of NCMRWF unified model vertical cloud structure with CloudSat over the Indian summer monsoon region [9882-7]

988208 Genesis of elevated aerosol loading over the Indian region [9882-8]

988209 Aerosols-cloud interaction during active-break cycle of Indian summer monsoon from satellite observations and cloud resolving model simulations [9882-9]

\section{SATELLITE DATA ASSIMILATION I}

$98820 \mathrm{~A}$ Recent results and proposed observing system simulation experiments (OSSE) to link research and operation [9882-11]

\section{SATELLITE DATA ASSIMILATION II}

9882 OD Reduction of uncertainty associated with future changes in Indian summer monsoon projected by climate models and assessment of monsoon teleconnections [9882-14]

9882 OE Impact of Megha-Tropiques SAPHIR radiance assimilation on the simulation of tropical cyclones over Bay of Bengal [9882-15]

9882 OF Impact of advanced technology microwave sounder data in the NCMRWF 4D-VAR data assimilation system [9882-16] 
SATELLITE DATA ASSIMILATION III

9882 0J Impact of EnVar hybrid assimilation using EnKF ensembles [9882-21]

9882 OK High resolution land surface response of inland moving Indian monsoon depressions over Bay of Bengal [9882-96]

REMOTE SENSING AND CLIMATE I

$98820 \mathrm{M}$ Quantifying and monitoring convection intensity from $\mathrm{mm}$-wave sounder observations [9882-23]

9882 OP Recent land use/land cover changes and their impact on the evolution and structure of thunderstorm in New Delhi [9882-26]

$98820 Q \quad$ Precipitation-aerosol relationship over the Indian region during drought and excess summer monsoon years [9882-27]

\section{ATMOSPHERIC AND OCEAN MODELING I}

$98820 \mathrm{X}$ Understanding hydrologic sensitivity and land-atmosphere interactions through remote sensing and high resolution regional model [9882-34]

\section{ATMOSPHERIC AND OCEAN MODELING II}

$98820 Z$ Improvement of systematic bias of mean state and the intraseasonal variability of CFSv2 through superparameterization and revised cloud-convection-radiation parameterization [9882-38]

988210 An effort to improve track and intensity prediction of tropical cyclones through vortex initialization in NCUM-global model [9882-39]

988213 Prediction of tropical cyclone over North Indian Ocean using WRF model: sensitivity to scatterometer winds, ATOVS and ATMS radiances [9882-42]

988214 Prediction of severe thunderstorms over Sriharikota Island by using the WRF-ARW operational model [9882-44]

POSTER SESSION

988217 Impact of GNSS-IPW observations on NGFS [9882-47]

988218 Aerosol-cloud interactions: effect on precipitation [9882-48]

9882 1C Impact of hyperspectral radiance in the simulation of tropical cyclone using NCUM model [9882-53]

iv 
9882 1D Assimilation of ASCAT winds using 4DVAR: an impact study [9882-54]

$98821 \mathrm{E} \quad$ Efforts in assimilating Indian satellite data in the NGFS and monitoring of their quality [9882-55]

$98821 \mathrm{H} \quad$ Scattering phase function for particulates-in-water: modeling and validation [9882-58]

$988211 \quad$ A review of recent evaluation of satellite estimates sea surface salinity in the tropical Indian Ocean [9882-59]

$98821 \mathrm{~J} \quad$ Height of warm core in very severe cyclonic storms Phailin: INSAT-3D perspective [9882-60]

9882 1M Impact of AWiFS derived land use land cover on simulation of heavy rainfall [9882-63]

988210 Forecasting of monsoon heavy rains: challenges in NWP [9882-65]

$98821 \mathrm{P} \quad$ Analysis and evaluation of Observing System Simulation Experiments (OSSEs) forecast data for Indian summer monsoon [9882-67]

9882 is Water vapor transport from the Indian monsoon region: the phenomenon of Atmospheric River [9882-70]

$98821 \mathrm{U}$ Possible development mechanisms of pre-monsoon thunderstorms over northeast and east India [9882-74]

988212 Effect of El-Nino on Southwest Monsoon 2015 [9882-79]

988220 Seasonal dynamics of circulation in Hooghly Estuary and its adjacent coastal oceans [9882-80]

988222 Onset of Indian Summer Monsoon: a retrospective analysis [9882-82]

988226 An automated fog monitoring system for the Indo-Gangetic Plains based on satellite measurements [9882-87]

988227 The spatio-temporal structures and role of low- and high-frequency intraseasonal modes in Indian Summer monsoon rainfall observed in TRMM data [9882-88]

988228 Relation between tropical cyclone heat potential and cyclone intensity in the North Indian Ocean [9882-89] 
Proc. of SPIE Vol. $9882988201-6$

Downloaded From: https://www.spiedigitallibrary.org/conference-proceedings-of-spie on 26 Apr 2023 Terms of Use: https://www.spiedigitallibrary.org/terms-of-use 


\section{Authors}

Numbers in the index correspond to the last two digits of the six-digit citation identifier (CID) article numbering system used in Proceedings of SPIE. The first four digits reflect the volume number. Base 36 numbering is employed for the last two digits and indicates the order of articles within the volume. Numbers start with 00, 01, 02, 03, 04, 05, 06, 07, 08, 09, OA, OB...0Z, followed by 10-1Z, 20-2Z, etc.

Abhik, S., OZ

Ashrit, Raghavendra, 10

Basu, Swati, $1 \mathrm{~J}$

Bhatla, R., 10

Bhattacharya, Anwesa, 09

C. K., Unnikrishnan, OP

Chakraborty, Arindam, 09, 27

Chandrasekar, Anantharaman, $\mathrm{OE}$

Chourey, Reema, 26

Dadhwal, V. K., 20

Dasari, Hari Prasad, 13

Deshpande, Medha, IP

Dodla, Venkata B., 13

Dudhia, Jimmy, $\mathrm{OZ}$

Emmitt, Dave, 1P

G., Mrudula, 1S, 1U, 1Z, 22

G., Papa Rao, 14

Ganai, Malay, $0 z$

Gautam, Ritesh, 26

George, John P., OF, 10, 1C, 1D

Gharai, Biswadip, 1M

Gopalakrishnan, Deepak, OE

Goswami, B. N., IP

Goswami, Bidyut B., $0 Z$

Gubbala, Chinna Satyanarayana, 13

Haddad, Ziad S., OM

Hardesty, Michael, IP

Harris, Andy, 04

lyengar, Gopal, 10

Jangir, B., 28

Jayakumar, A., 07

Jisesh, A. S., 07

Johny, C. J., 0J, 17

K. U., Vidhulakshmi, 1 Z

Kacimi, Sahra, OM

Karmakar, Nirupam, 27

Karri, Srinivasarao, $1 \mathrm{M}$

Khairoutdinov, Marat, $\mathrm{OZ}$

Kitoh, Akio, OD

Koner, Prabhat K., 04

Krishnamurti, T. N., 1P

Kumar, Anil, OX

M., Dhanya, OE

M., Rajasekhar, 14

M., Rajeevan, 14

Ma, Zaizhong, IP

Mahakur, M., $\mathrm{OZ}$

Mahapatra, D. K., 11

Maheskumar, R., 18
Mallick, Swapan, OF, 10, 1D

Mamgain, Ashu, 07, OP

Masutani, Michiko, OA, IP

Mishra, Shashank Kr., 20

Mitra, Ashis K., 11

Mohan, Mannil, 08

Mohandas, Saji, 07

Momin, Imranali M., 11

Mukhopadhyay, P., 0Z, 1P

Nanjundiah, Ravi S., 27

Narayanan, Sunanda, $1 \mathrm{U}$

Nayak, Gourav, 20

Nayak, R. K., 20

Pandey, Satyendra K., 05

Patil, Dinesh, 26

Pattnaik, S., OK

Phani Murali Krishna, R., $\mathrm{OZ}$

Prasad, V. S., OE, 0J, 17, 1E, 1J

Prijith, S. S., 08

R., Pushpa Saroja, 14

Raghav R., Sree, 15

Rajagopal, E. N., 07, 0J, OP, 10, 11, 1J, 10

Rajendran, Kavirajan, OD, OQ

Rajesh, P. V., OK

Rakhi, R., 07

Ramakrishna, S. S. V. S., 14

Rani, S. Indira, OF, 1C, 1D, IJ

Rao, P. V. N., 08, $1 \mathrm{M}$

Riishojgaard, Lars Peter, IP

Rizvi, Sarwar, 26

Routray, A., 10, 1C

S., Sruthi, 22

Sahu, Sanjay Kumar, $1 \mathrm{H}$

Sai Krishna, S. V. S., $1 M$

Sawaya, Randy S., OM

Shanmugam, Palanisamy, $1 \mathrm{H}$

Sharma, Kuldeep, 10

Singh, Manoj, 26

Singh, Sanjeev Kumar, OE, $1 \mathrm{E}$

Singh, Vivek, 10, 1C

Sodhi, Jagdeep Singh, 0J

Srinivas, Desamsetti, OF, 13, 1D

Steward, Jeffrey L., OM

Surendran, Sajani, OD, OQ

Swain, D., 28

Sy, Ousmane O., OM

T., Sreeshna, 14

Takle, Jasmine, 18

Udaya Bhaskar, T. V. S., 28 
V. B., Arya, $O Q$

Varghese, Stella Jes, OD

Venugopal, $\vee ., 09$

Vinoj, V., 05

Vishwanathan, Gokul, $1 \mathrm{U}$

Proc. of SPIE Vol. $9882988201-8$

Downloaded From: https://www.spiedigitallibrary.org/conference-proceedings-of-spie on 26 Apr 2023 Terms of Use: https://www.spiedigitallibrary.org/terms-of-use 


\title{
Symposium Committees
}

\author{
Symposium Chairs
}

Upendra Singh, NASA Langley Research Center (United States)

Vinay Dadhwal, Indian Space Research Organisation (India)

KJ Ramesh, Ministry of Earth Sciences (India)

Symposium Co-chairs

Toshio Iguchi, National Institute of Information and

Communications Technology (Japan)

Jiancheng Shi, Institute of Remote Sensing and Digital Earth

(China)

Honorary Symposium Chairs

A. S. Kiran Kumar, Indian Space Research Organisation (India)

Charles F. Bolden, National Aeronautics and Space Administration (United States)

Jean-Yves Le Gall, Centre National d'Études Spatiales (France)

Naoki Okumura, Japanese Aerospace Exploration Agency

(Japan)

Dazhe Xu, China National Space Administration (China)

Madhavan N. Rajeevan, Ministry of Earth Sciences (India)

Guanhua Xu, Ministry of Science and Technology (China)

Alain Ratier, EUMETSAT (Germany)

Symposium Technical Program Chairs

George J. Komar, National Aeronautics and Space

Administration (United States)

Kohei Mizutani, National Institute of Information and

Communications Technology (Japan)

Tapan Misra, Indian Space Research Organisation (India)

S.S.C. Shenoi, Ministry of Earth Sciences (India)

Xiaohan Liao, China National Remote Sensing Center (China)

Symposium International Organizing Committee

Michael H. Freilich, Chair, National Aeronautics and Space Administration (United States)

Jack A. Kaye, National Aeronautics and Space Administration (United States)

Clayton P. Turner, NASA Langley Research Center (United States) 
David F. Young, NASA Langley Research Center (United States)

Y. V. N. Krishnamurthy, Indian Space Research Organisation (India)

M. Annadurai, Indian Space Research Organisation (India)

Saroj K. Jha, National Hydrographic Centre (India)

E. N. Rajagopal, National Centre for Medium Range Weather Forecasting (India)

M. Ravichandran, National Centre for Antarctic and Ocean Research (India)

Teruyuki Nakajima, Japan Aerospace Exploration Agency (Japan)

Toshiyoshi Kimura, Japan Aerospace Exploration Agency (Japan)

Akimasa Sumi, National Institute for Environmental Studies (Japan)

Haruhisa Shimoda, Tokai University (Japan)

Peng Gong, Tsinghua University (China)

Shunling Liang, Beijing Normal University (China)

Local Organizing Committee

Shibendu S. Ray, Mahalanobis National Crop Forecast Centre (India)

Mahendra Bhutiyani, Defence Terrain Research Laboratory (India)

Vivek Singh, Indian Space Research Organisation (India)

Shiv Prasad Aggarwal, Indian Space Research Organisation (India)

Sameer Saran, Indian Space Research Organisation (India)

Jagvir Singh, Ministry of Earth Sciences (India)

Rishi Kumar, Ministry of Earth Sciences (India)

Rabi N. Sahoo, Indian Agricultural Research Institute (India)

Jai K. Garg, Guru Gobind Singh Indraprastha University (India)

Pawan Kumar Joshi, Jawaharlal Nehru University (India)

Madan M. Kimothi, Mahalanobis National Crop Forecast Centre (India) 


\title{
Conference Committee
}

\author{
Conference Chairs
}

Tiruvalam N. Krishnamurti, Florida State University (United States)

Madhavan Nair Rajeevan, Indian Institute of Tropical Meteorology (India)

Conference Co-chairs

Riko Oki, Japan Aerospace Exploration Agency (Japan)

Yihui Ding, China Meteorological Administration (China)

Conference Program Committee

Ziad Haddad, Jet Propulsion Laboratory (United States)

Guosheng Liu, Florida State University (United States)

Michiko Masutani, Joint Center for Satellite Data Assimilation

(United States) and Earth System Science Interdisciplinary Center, University of Maryland (United States)

Ravi S. Nanjundiah, Indian Institute of Science (India)

Session Chairs

1 Aerosol, Cloud, and Precipitation I

Tiruvalam N. Krishnamurti, Florida State University (United States)

Ana P. Barros, Duke University (United States)

2 Aerosol, Cloud, and Precipitation II

Madhavan Nair Rajeevan, Indian Institute of Tropical Meteorology (India)

Tiruvalam N. Krishnamurti, Florida State University (United States)

3 Satellite Data Assimilation I

Ziad Haddad, Jet Propulsion Laboratory (United States)

Kavirajan Rajendran, CSIR Fourth Paradigm Institute (India)

4 Satellite Data Assimilation II

Ravi S. Nanjundiah, Indian Institute of Science (India)

Thara V. Prabhakaran, Indian Institute of Tropical Meteorology (India)

5 Satellite Data Assimilation III

Ravi S. Nanjundiah, Indian Institute of Science (India)

Thara V. Prabhakaran, Indian Institute of Tropical Meteorology (India) 
6 Remote Sensing and Climate I

Michiko Masutani, National Oceanic and Atmospheric Administration (United States)

Takuji Kubota, Japan Aerospace Exploration Agency (Japan)

7 Remote Sensing and Climate II

Raghavan Krishnan, Indian Institute of Tropical Meteorology (India)

Shoken Ishii, National Institute of Information and Communications Technology (Japan)

$8 \quad$ Atmospheric and Ocean Modeling I

Guosheng Liu, Florida State University (United States)

P. N. Vinayachandran, Indian Institute of Science (India)

9 Atmospheric and Ocean Modeling II

Arindam Chakraborty, Indian Institute of Science (India)

Anil Kumar, Space Applications Centre (India) 